\title{
Perception of Parents and Students on Education in Emergencies during the COVID-19 Pandemic under Thimphu Dzongkhag 2020
}

\author{
Jamyang $^{1}$, Tendi Wangdi ${ }^{2}$ \\ ${ }^{1}$ Principal, Hongtsho Primary School; Thimphu Dzongkhag \\ Email: jamyangura72@gmail.com \\ ${ }^{2}$ Principal, Tshaluna Primary School; Thimphu Dzongkhag \\ Email: tendiwangdi11@education.gov.bt
}

\begin{abstract}
Received: 09 Nov 2021; Received in revised form: 30 Dec 2021; Accepted: 20 Jan 2022
(C)2022 The Author(s). Published by TheShillonga. This is an open access article under the CC BY license

(https://creativecommons.org/licenses/by/4.0/)
\end{abstract}

\begin{abstract}
Globally COVID-19 pandemic has disrupted the normal functions of schools. Online learning is a new concept in Bhutan. Nonetheless, teaching and learning happened using various online learning platforms. This study examines the students', parents', and school's perceptions about the effectiveness of online Education in the Emergencies teaching-learning environment. A total of 690 students, 677 parents, and 12 schools participated. The survey questionnaire prepared by the Education Monitoring Division, Ministry of Education was used to collect data. The findings of the study suggest that $66 \%$ of students enjoyed EiE lessons. Although, $70 \%$ of the student respondents reported that their parents could help them in online learning, in reality only $62 \%$ of parents provided academic-related support to their children. The findings reiterated that the most popular application during the online learning was WeChat followed by Google Classroom and a slow internet connection and high internet data subscription charges were cited as major challenges for both teachers and students alike. Further, the results of the predictive analysis suggest $11 \%$ variability that can be accounted for by studying 1-2 hours in a day. Interaction and communication with teachers to clear their doubts more than four times a week is accounted for an $18 \%$ improvement in the effectiveness of online learning. The third predictor supports and guidance received from parents in learning could be accounted for $24 \%$ effectiveness, while the final predictor variable time spent on playing video games and other online games did not contribute to change in $r$ square value.
\end{abstract}

Keywords - Education in Emergency, Self-Instructional Materials, online learning environment, Education Monitoring Division, Ministry of Education.

\section{INTRODUCTION}

The COVID-19 pandemic has forced universities, colleges, and schools all over the world to make modifications in their systems of delivering classes (Zhou et al., 2020). More than ever, the use of technology to leverage online learning has increased dramatically (Adarkwah, 2020; Bergdahl \& Nouri, 2020; Hill \& UribeFlorez, 2020). Online education continues to become the primary tool in delivering undisrupted lessons around the globe (Kerres, 2020; Onyema, 2020). Also, one of the major impacts on the education systems was the indefinite closures of schools in more than 100 countries worldwide (Ahmed, 2020; Kerres, 2020; Onyema, 2020).

The Bhutanese education system, for the first time, witnessed a substantial pedagogical shift in the teaching and learning processes. Online learning is a new concept in Bhutan. Teachers in Bhutan, like in many other countries, were pushed beyond their comfort zones and are compelled to replace the instructional time loss through online learning (Dorji, 2020). As a result of COVID-19 regardless of teacher-student readiness, in many countries classes have begun teaching remotely, using online learning platforms (Bergdahl \& Nouri, 2020; OECD, 2020).

1.1 Background (Bhutanese Education in the wake of COVID-19)

The first positive case of COVID-19 in Bhutan was detected on $5^{\text {th }}$ March 2020 (Gyem et al., 2020). In the wake of it, the government closed all the schools in four western districts in the country for two weeks. With the 
dramatic rise of imported positive cases on $18^{\text {th }}$ March 2020, the government declared all the schools and institutions to remain closed until further order from the government. Subsequently, a sharp rise of COVID positive cases led to a complete closure of primary and lower schools for the academic year 2020 (Ministry of Education [MoE], 2020 b).

MoE in collaboration with Royal Education Council and Bhutan Council for School Examination and Assessment (BCSEA) responded to the situation with the "adaptation and prioritization of curriculum to deliver desired learning outcomes and facilitate students' continuity of education" (MoE, 2020, a). While the curriculum has been planned and delivered through different platforms such as national broadcast media (Bhutan Broadcasting Service and radio), YouTube, Google Classroom, and print media, ensuring the effectiveness of the lessons were left to the teachers. The MoE developed and designed 'Self-instructional materials' (SIM) and were distributed to students who had no access to cable and internet connections. Teachers were entrusted by the Ministry to provide guidance and support to students using Google Classroom for classes IV - XII, and other social media for classes PP - III (MoE, 2020, a).

\subsection{Significance of the Study}

The study on Education in Emergencies will have a direct bearing on the school closure during the emergencies at the national and Dzongkhag levels. Further, it will support the future course of plans and activities required to adopt during such emergencies. The study will examine the impacts of virtual education in Bhutan ever since the closure of schools on 18 March 2020. Findings will also reveal the associated merits and challenges of the operation of Education in Emergencies.

\subsection{Research Objectives}

This study aims to:

- determine the overall scenario of education in Thimphu Dzongkhag during the COVID-19 pandemic after the closure of schools from 18 March 2020.

- discover the effectiveness of Education in Emergencies delivered through different mediums of teaching and learning.

- espouse relevant educational pathways to navigate continuity of Education in Emergencies during any pandemic in the future

\section{REVIEW OF THE RELATED LITERATURE}

Education in Emergency refers to education for populations affected by unforeseen situations such as armed conflict or natural disasters (Sinclair, 2001). It is a set of linked project activities, which enable education to continue even in times of acute crisis or long-term instability (Nicolia, 2003). The COVID-19 has disrupted the normal educational settings across the globe with no exception to Bhutan. Thus, the government and public institutions had to operate schools and institutions by applying the principles of Education in Emergencies.

During the time of emergencies, the most affected sections of the society are the children who are in rural areas, children with disabilities, and those children who are left alone by themselves. Children who are out of school for an extended time are less likely to return to the classroom. Many children will expose themselves to threats and violence. Threats and violence include separation from their family and losing their home, forced or voluntary conscription, and sexual violence. Children either are prone to affect psychologically, by their personal experiences, or through the stresses placed on their families and communities. Because of threats and violence, children might attend into petty trade, casual labor, childcare, prostitution, and or active participation in the conflict (Nicolia, 2003). The emergencies also have a huge impact on teachers. It leads to increased teacher attrition and absenteeism (Education in emergencies, n.d.). During such time of emergencies, the situation is further constrained by problems such as insecurity and household poverty, poor educational quality leading to early dropout, and the breakdown of educational management systems (Sinclair, 2001).

Education can help children to reduce their vulnerability by building new lives based on the three core principles: the child's right to education, protection, and the community's priority of education. Schools are not just for a place of academic learning. Meaningful engagement such as recreational activities for creativity and socializing with peers are all essential elements of the experience (Nicolia, 2003). It may be more difficult to meet these principles, however, cannot be ignored (Sinclair, 2001). Therefore, schooling is one of the most important means of restoring a sense of normalcy to the lives of children. It contributes significantly to overcoming the psychological and other forms of distress that children would have experienced (Education in emergencies, n.d.). Despite the enormous challenges and disruptions an emergency brings, it can also open up opportunities for universal reform in the education system. Such emergency as COVID-19 has propelled reform in which immediate changes are rendered possible. Emergencies can thus provide an opportunity for transformation and adapting to new normal. Therefore, education possesses enormous value for its own sake, and all the children including adults who are affected by the 
emergencies have the right to education. Eventually, education is indispensable in times of any emergency settings to prepare societies for imminent post-conflict or post-disaster reconstruction, social and economic development (Talbot, 2013).

\section{METHODOLOGY}

The researchers adopted a mixed method to carry out the study. This method offers comprehensive information and rich conclusion from the quantitative and qualitative data. The triangulation of data avoids potential biases arising from the use of a single methodology (Forbes \& Heale, 2013). Furthermore, the employment of varieties of data collection methods strengthens each type of data collected and minimizes the weaknesses of any single approach employed by increasing its validity and reliability (An overview of quantitative and qualitative data collection methods, n.d).

\subsection{Participants}

The selection of participants for this study was based on convenience sampling. Out of 4123 students, a $20 \%$ sampling representation was considered (690) student respondents and (677) parents. The details on the number of schools, students, and parents are presented in Table 1.

Table 1: Details of descriptive statistics

\begin{tabular}{|c|c|c|c|c|c|}
\hline Sl.No. & School & Students & $\begin{array}{l}\text { Total } \\
\text { Students }\end{array}$ & $20 \%$ & Parents \\
\hline 1 & Bjemina PS & 35 & 176 & 35.2 & 34 \\
\hline 2 & Genekha LSS & 15 & 311 & 62.2 & 19 \\
\hline 3 & Hongtsho PS & 32 & 156 & 31.2 & 35 \\
\hline 4 & Lingzhi PS & 12 & 56 & 11.2 & 12 \\
\hline 5 & Sisina PS & 41 & 204 & 40.8 & 42 \\
\hline 6 & Tshaluna PS & 8 & 43 & 8.6 & 8 \\
\hline 7 & $\begin{array}{l}\text { Yum Thujizam } \\
\text { PS }\end{array}$ & 15 & 163 & 32.6 & 15 \\
\hline 8 & $\begin{array}{l}\text { Khasadrapchu } \\
\text { MSS }\end{array}$ & 168 & 949 & 189.8 & 169 \\
\hline 9 & $\begin{array}{l}\text { Kuzhugchen } \\
\text { MSS }\end{array}$ & 101 & 489 & 97.8 & 100 \\
\hline 10 & $\begin{array}{l}\text { Yangchengatshel } \\
\text { MSS }\end{array}$ & 87 & 550 & 110 & 87 \\
\hline 11 & Desi HSS & 100 & 586 & 117.2 & 86 \\
\hline \multirow[t]{2}{*}{12} & Wangbama HSS & 76 & 440 & 88 & 70 \\
\hline & Total: & 690 & 4123 & 824.6 & 677 \\
\hline
\end{tabular}

\subsection{Instrumentation}

The instruments used are based on Education in Emergencies (EiE) survey questionnaire developed by the Education Monitoring Division, Ministry of Education. The instruments sought responses from students, schools, and parents covering many dimensions related to online teaching and learning processes.

\subsection{Measurement scales}

Since all of the measurement scales for parents and student surveys were mostly at the level of the categorical variable, therefore to have a data fit for analysis, most of the questions had to be coded and converted either into an ordinal or a continuous variable. Therefore, using the principal component factor analysis technique, all items for students (20 items) and parents (11) items were factor-loaded. The analysis results showed that at Eigenvalue $>=1$, with the "Principal Axis Factoring" method, and the "Promax" rotation method with Kaiser Normalization, there could be 8 factors extracted from 31 observed variables, and the extraction variance was $60.2 \%$.

The rationale behind conducting principal components analysis was to reduce the dimensions as some questions in the survey (students and parents) were redundant and as such similar items were collated together. The eight extracted themes generated were;

a. Effectiveness: Effectiveness is defined as the degree to which something is successful in producing the desired result. In this regard, effectiveness refers to the online learning method. For this theme, item 1, item 2, and item 20 (from students), and item 9 and item 11 (from parents) were utilized.

b. Time Use: The second identified theme is 'time use.' Time use can be understood as allocation of time for online lessons and assignments, reading, playing the game, and the number of hours rendered in helping their parents. It also considers parents' views on the number of hours spent by their children on academic learning, reading, playing online games, helping parents, and physical activities at home. Items included under this theme are items 3,14, 15,19 (Students) and items $2,3,4,5$, and 6 from the parent's questionnaire.

c. Support and Engagement: This theme encompasses the support provided by schools, teachers, and parents in engaging students for learning. It also includes the level of effectiveness of functioning of EiE programs at the school level and support provided to the SEN students. The 
pooled items for this particular theme are items 4, 12, 13 (from the student questionnaire) and items 7 and 10 from parent's questions.

d. Accessibility: Accessibility refers to whether students have access to academic learning resources such as TV, smartphone, SIM, video, radio, textbooks, and MP3 player with support from Dzongkhag Education Sector. Items included within this theme are items 5, 6, 9, and 18 from students' questions.

e. Assessment: Assessment literacy has been recognized as an important tool for teachers. It helps them useful information about student learning to teach more effectively by responding to students' learning needs. Stiggins (1991) defines assessment as a set of knowledge about educational assessment and the skills required to apply that knowledge to measure student learning. For instance, some of the examples could be the assessment of students' learning by teachers from the lessons/task given on $\mathrm{TV}$, radio, SIM, or through any other social media. Only item no 10 from student questions was found fit for this theme.

f. Interaction and communication: Interaction and communication can be referred to as a frequency and mode of interaction between teacher and students for the teaching and learning process. Item included were items 8, and 11 (students), and items (1 and 8) for the parents.

g. Impact of school closure: This theme explains the impact of school closure on learning and the excitement level of the learners to join the school on reopening. Item no 16 and 17 from students' questions were used in this theme. However, for the school questionnaire, a separate thematic analysis based on the response was carried out as the responses sought were qualitative.

h. Challenges and Recommendations: 'Challenge' may be understood as the difficulties encountered by students while using different online learning applications. Item no 7 from the student questionnaire was found to fit under this theme.

\section{DATA COLLECTION AND ANALYSIS}

Firstly, an email copy of the survey questionnaire received from the Education Monitoring Division was sent to respective schools. Then, the schools were tasked to collect data from students and parents along with 6 items related to school. The data was analyzed using Microsoft Excel 19 and SPSS version 23 conventions. Mostly the data was suitable for descriptive analyses however stepwise regression was used to predict the effectiveness of EiE was considered as the dependent variable while the Average hours I spend on online lessons and assignments per day, How frequently do you contact your teachers in a week? What type of support do you receive from teachers? How many hours do you spend on video games and other online games? How do you support your child's learning? were treated as the predictor variable to compute the predictive analysis.

\section{DISCUSSION}

\subsection{Effectiveness}

It can be seen from Figure 1a that 459 students enjoy EiE lessons while 228 did not enjoy EiE learning. The results also indicated that 564 student respondents perceived learning to have taken place as opposed to 122 students not enjoying the EiE delivered lessons. At the same time, the differences in online learning based on parent reports, not a statistical significance could be found. Majority of students perceived online teaching and learning was ineffective while the views on general EiE learning, no differences could be found (for details see Figure 1b).

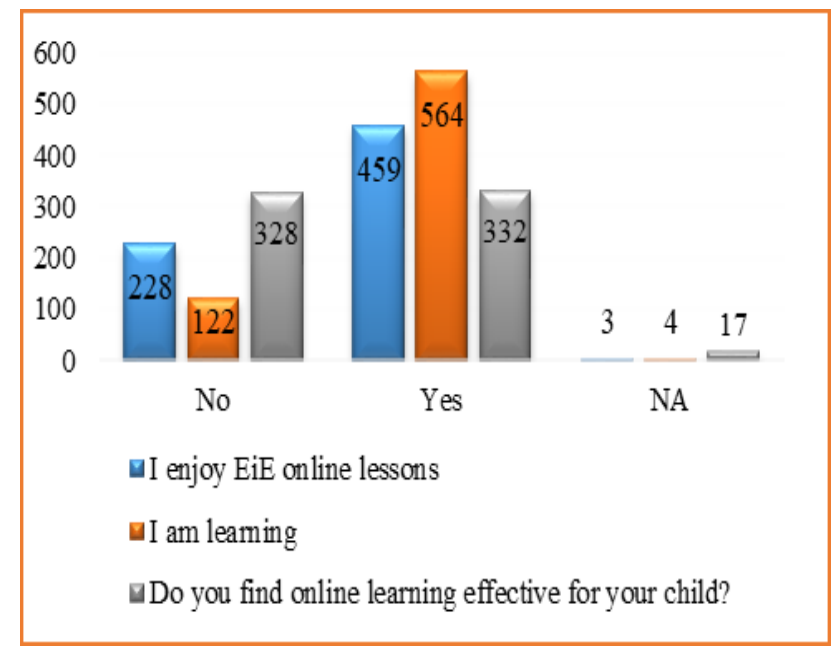

Fig. 1a: Effectiveness of EiE 


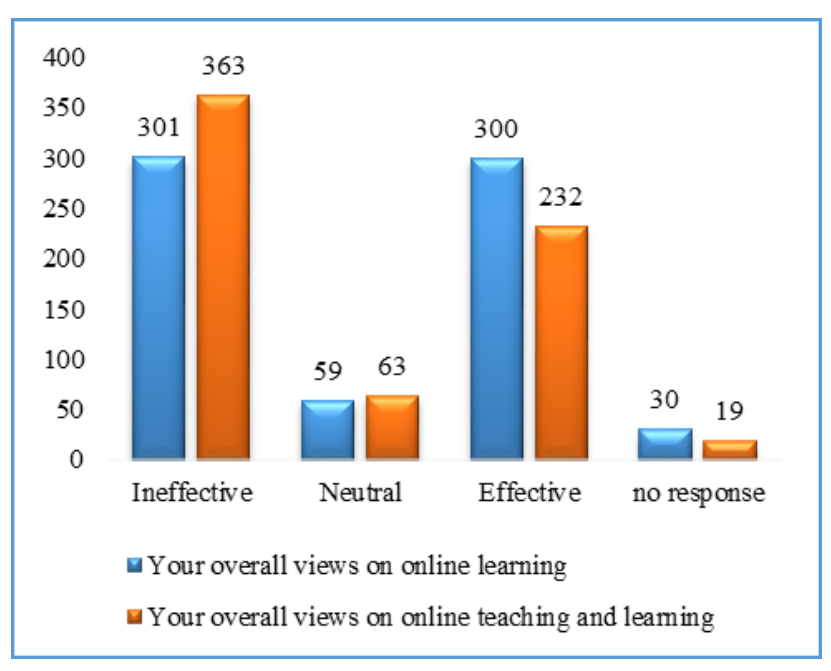

Fig. 1b: Effectiveness of EiE

A stepwise regression analysis was run to determine how much of the variation in the dependent variable is explained by the independent variable. In this regard, the effectiveness of EiE was considered as the dependent variable against the 5 predictor variables;

1. Average hours I spend on online lessons and assignments per day;

2. How frequently do you contact your teachers in a week?

3. What type of support do you receive from teachers?

4. How many hours do you spend on video games and other online games?
5. Parents' support in learning as the predictor variables to compute the predictive analysis.

The results of the predictive analysis showed $11 \%$ of the variance can be accounted for by studying 1-2 hours in online learning. Interaction and communication with teachers to clear their doubts more than four times a week is accounted for an $18 \%$ improvement in the effectiveness of online learning. The third predictor supports and guidance received from parents in learning could be accounted for $24 \%$ effectiveness, while the final predictor variable time spent on playing video games and other online games did not contribute to change in $r$ square value.

\subsection{Time Use}

The data in Table 2 compares to time spent by students on various activities including time spent on learning. In general, the most noticeable average time spent on online learning is 0-60 minutes per day while there is a gradual decline in students devoting more than three hours for the learning activity in a day. Besides, student engagement in learning activities, a considerable amount of time is also spent by children in helping parents, playing online games, and engaging in physical activities. The highlight of this table is the stark similarity between reports by the parents and students, for instance, the average time spent learning and playing online games.

Table 2: Time Use

\begin{tabular}{|c|c|c|c|c|c|c|c|}
\hline & Never & $\begin{array}{l}01- \\
60 \mathrm{~min}\end{array}$ & $\begin{array}{c}61- \\
120 \mathrm{~min}\end{array}$ & $\begin{array}{l}121- \\
180\end{array}$ & $\begin{array}{l}\text { 181- } \\
240 \mathrm{~min}\end{array}$ & $\begin{array}{c}241 \\
\text { and } \\
\text { above }\end{array}$ & $\begin{array}{c}\text { No } \\
\text { response }\end{array}$ \\
\hline $\begin{array}{l}\text { Average hours I spend on online } \\
\text { lessons and assignments per day }\end{array}$ & 28 & 268 & 180 & 114 & 39 & 60 & 1 \\
\hline $\begin{array}{l}\text { How many hours do you spend } \\
\text { reading } \\
\text { books/newspapers/magazines/etc. in } \\
\text { a week? }\end{array}$ & 24 & 338 & 142 & 80 & 24 & 79 & 3 \\
\hline $\begin{array}{c}\text { How many hours do you spend on } \\
\text { video games and other online games? }\end{array}$ & 105 & 287 & 129 & 78 & 28 & 60 & 3 \\
\hline $\begin{array}{c}\text { No. of hours you spend supporting } \\
\text { your parents in a day }\end{array}$ & 6 & 214 & 116 & 113 & 56 & 178 & 7 \\
\hline $\begin{array}{c}\text { How long does your child spend time } \\
\text { on learning subjects in a day on } \\
\text { average? }\end{array}$ & 0 & 195 & 208 & 160 & 67 & 45 & 2 \\
\hline
\end{tabular}




\begin{tabular}{|c|c|c|c|c|c|c|c|}
\hline $\begin{array}{l}\text { How many hours does he/she spend } \\
\text { on reading } \\
\text { books/newspapers/magazines, etc. in } \\
\text { a day? }\end{array}$ & 28 & 441 & 142 & 40 & 12 & 14 & 0 \\
\hline $\begin{array}{c}\text { How long does he/she engage in } \\
\text { helping the family? }\end{array}$ & 30 & 336 & 131 & 78 & 34 & 58 & 10 \\
\hline $\begin{array}{l}\text { How long does he/she engage in } \\
\text { physical games and activities? }\end{array}$ & 58 & 287 & 146 & 90 & 43 & 44 & 9 \\
\hline $\begin{array}{l}\text { On average, how long does he/she } \\
\text { engage in video games and other } \\
\text { online games in a day? }\end{array}$ & 92 & 265 & 120 & 105 & 38 & 47 & 10 \\
\hline
\end{tabular}

\subsection{Support and engagement}

As can be seen from Figure 2, $70 \%$ of student respondents reported that their parents could help them in online-related learning activities. Furthermore, the findings from Figure 5 indicate that close $67 \%$ of parents reported that they helped children in their academic-related tasks. Nonetheless, in a true sense, only $62 \%$ of parents provided academic-related support, for instance helping children with their assignments and homework activities. On the contrary, little more than $8 \%$ of parents did not provide any assistance towards child's learning. The results also showed only $37 \%$ of parents provided data recharges to their children, out of which $47 \%$ of parents sought student data discounts (compare Figure 5 for details). It can also be seen that the majority of parents reported spending between $\mathrm{Nu}$. $400-600$ in a month, while $17 \%$ of parents stated spending significantly more than $\mathrm{Nu} .1800$ and above for the data recharges (See Figure 4). Whilst for teachers, besides providing academic support, some teachers reportedly provided students with data recharges.

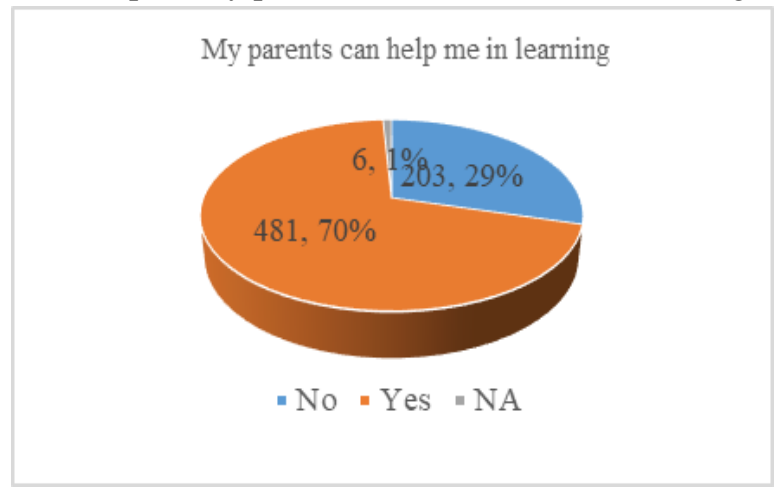

Fig. 2

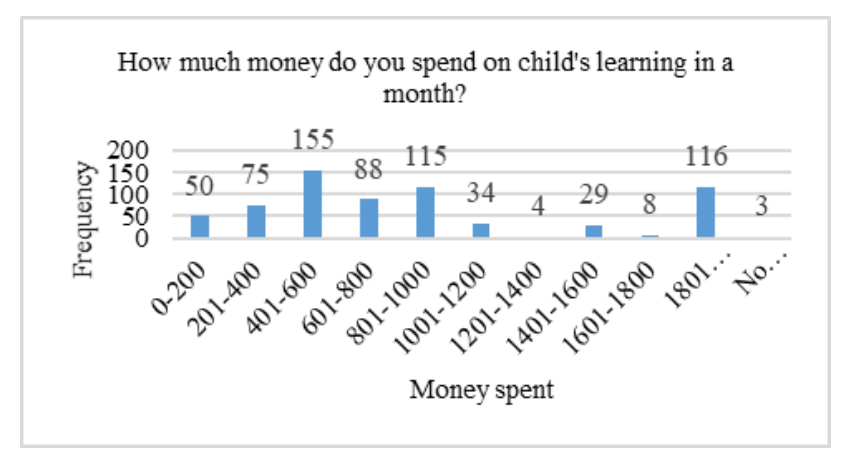

Fig. 3

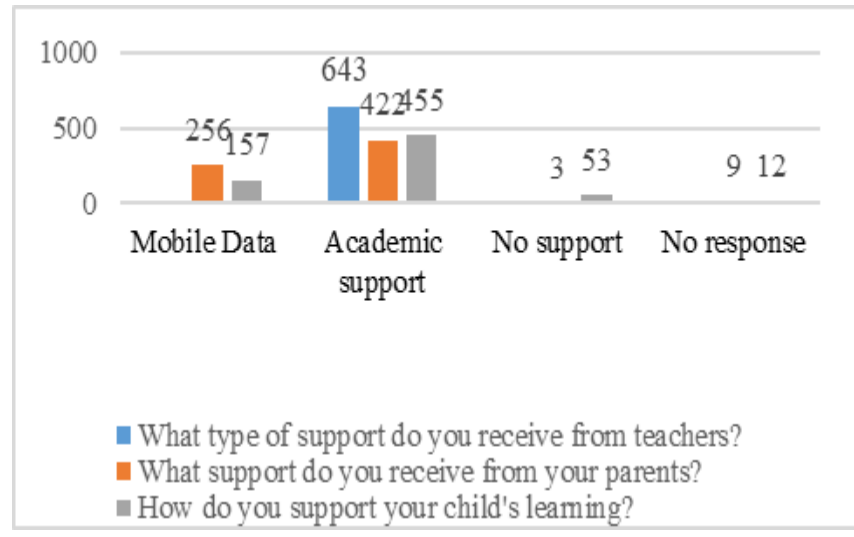

Fig. 4

Did you avail $60 \%$ discount data service?

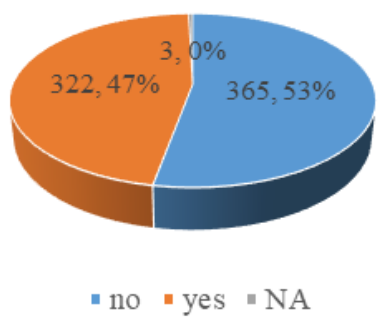

Fig. 5 


\subsection{Accessibility}

Figure 6 illustrates statistics related to accessibility to various learning resources by the students. Out of 690 student responses, a substantial number of students (628) have access to text books, out of which 63 students reported having access SIM. The data also suggests that a small number of children accessed lessons delivered in formats such as videos, radio, and other learning forms while on the contrary, phones seemed to the most popular preferred medium to access online learning by the students. With the students who used phones to interact and engage with lesson contents, by far the most popular application of connection was the WeChat and the google classroom applications (refer Figure 7) and the least used phone app were the WhatsApp.

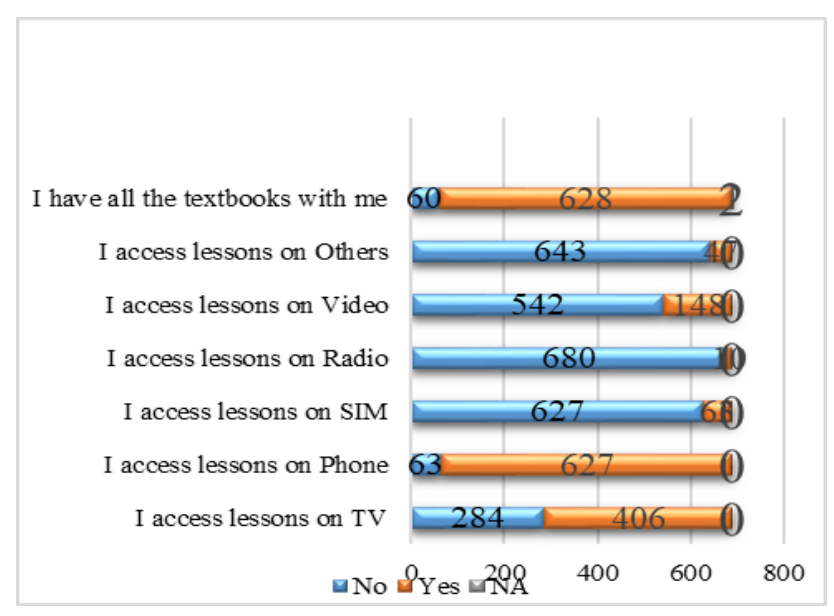

Fig. 6

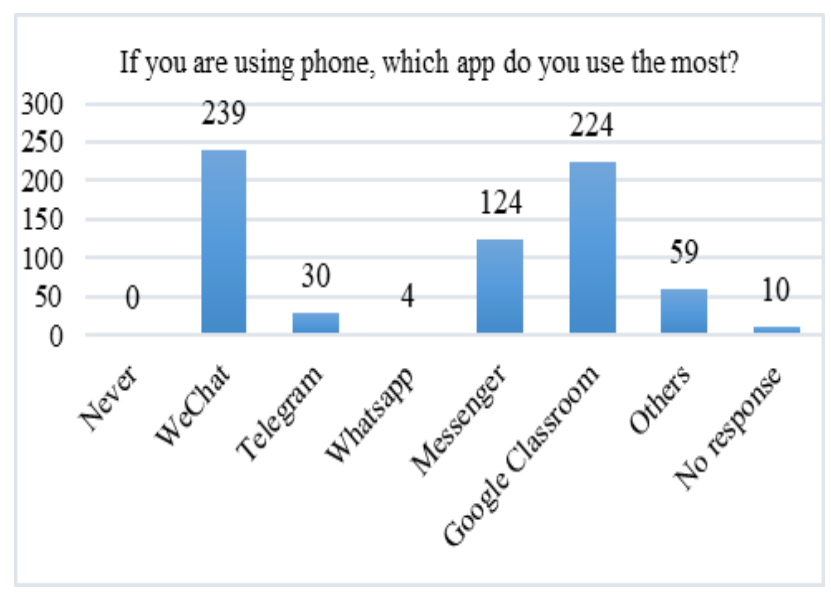

Fig. 7
Do teachers assess tasks given in TV, Radio, SIM lessons?

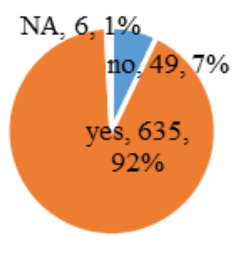

- no " yes " NA

Fig. 8

\subsection{Interaction and communication}

The data within this theme reports on the frequency, and the medium of communication used by students to clarify their queries related to learning. According to Figure 9, $42 \%$ of students reported contacting teachers once a week while approximately $13 \%$ of students reported having contacted teachers more than four times a week. The data from (Figure 10) further substantiates with $86 \%$ of parents supporting the claim. The data in Figure 11 demonstrates that teachers remain to be the top contact point for students (44\%) when it comes to clarifying their learning doubts, followed by $28 \%$ reporting using other means to solve their doubts. Parents (5\%), siblings and relatives (7\%), and friends contributing almost (10\%) also contributed. A close to $44 \%$ of parents reported that the mode of interaction was we chat and with fewer than $7 \%$ using google classrooms and other social networking applications (Figure 12).

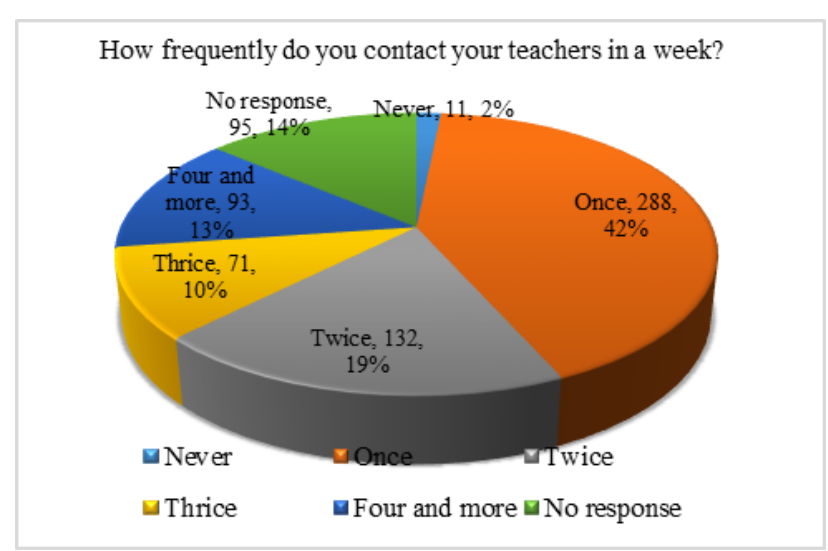

Fig. 9

\subsection{Assessment}

The pie-chart in Figure 8 illustrates that $92 \%$ of teachers assessed the learning tasks assigned to students. 


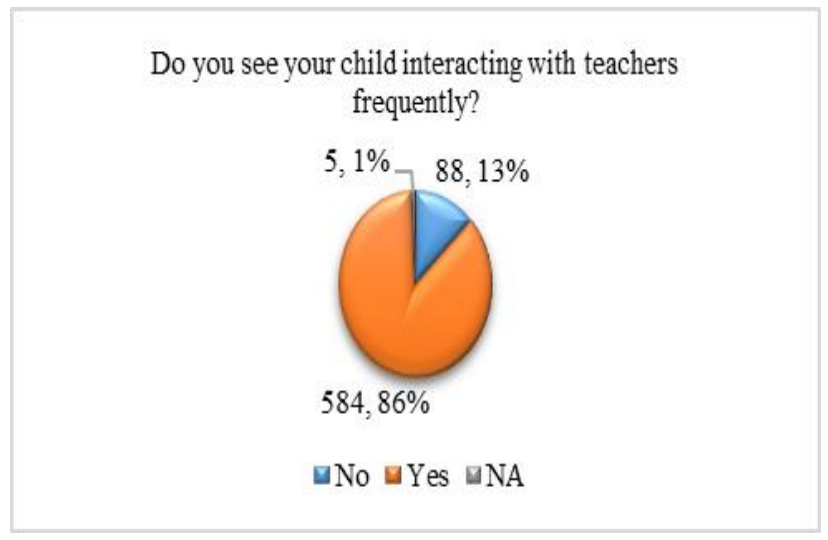

Fig. 10

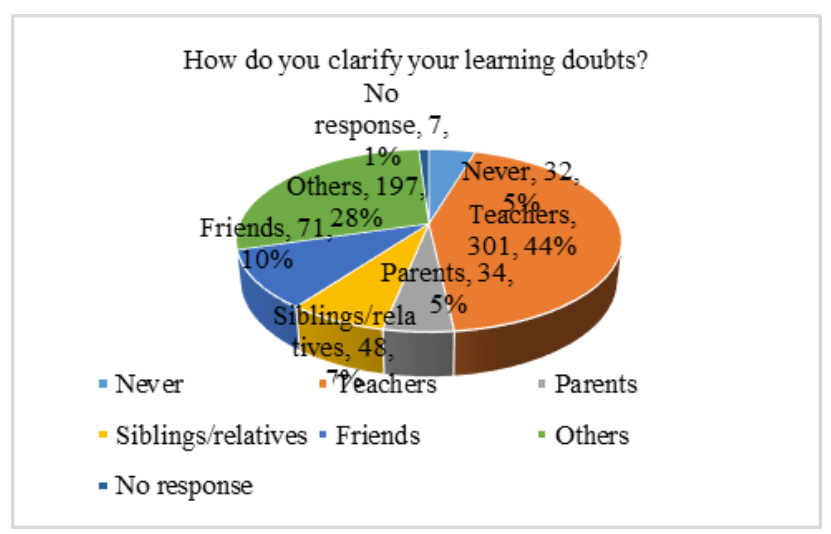

Fig. 11

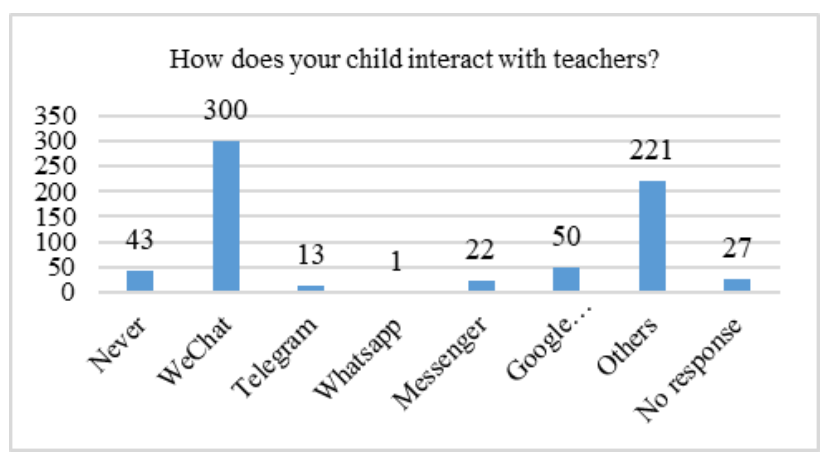

Fig. 12

\subsection{Impact of school closure}

The data in Figure 13 provides information on impact of school closure. The data shows rather a striking difference in terms of responses. More than $71 \%$ reported that their interest in studies was affected as a result of school closure as opposed to $27 \%$ reporting no affect. Despite substantial disruption, still $90 \%$ of students are looking forward to returning to resume schools.

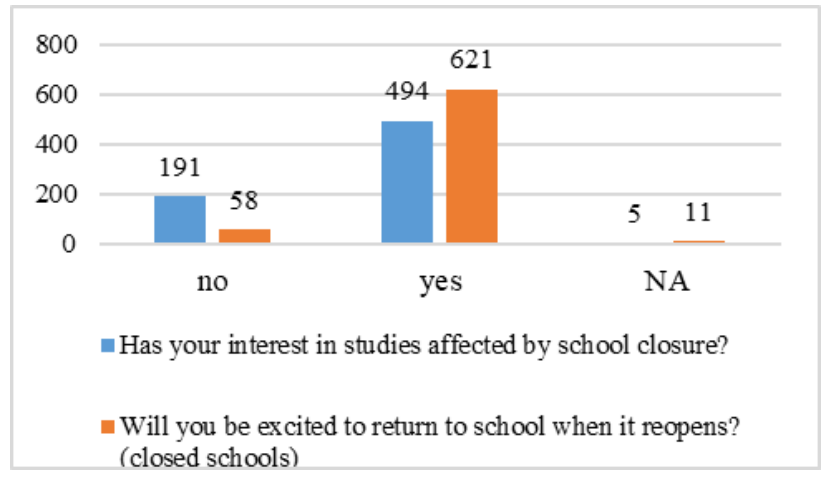

Fig. 13

\section{CHALLENGES}

A total of $51 \%$ of student respondents had difficulties using the learning using various applications

\section{Do you face challenges in using different apps?}

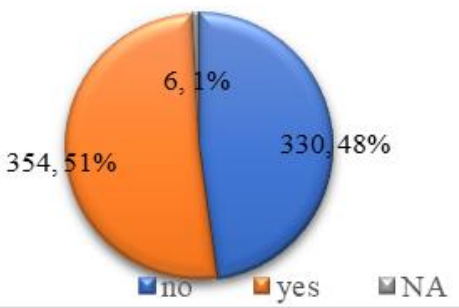

Fig. 14

Finally, the summary of parents and students' perceptions on EiE is presented in Table 3. 
Table 3: Perceptions of schools on EiE learning and teaching

\begin{tabular}{|c|c|c|}
\hline Sl.No & Themes & Views and comments \\
\hline 1 & $\begin{array}{l}\text { Strengths of } \\
\text { EiE }\end{array}$ & $\begin{array}{l}\text {-Student engagement and exposure to digital media devices. } \\
\text {-It provides platform for accessing online resources } \\
\text { - Reduced syllabus makes learning interesting } \\
\text { - Could provide continued learning to all the children irrespective of where they live } \\
\text { - Teachers are confident with EiE curriculum } \\
\text {-Could foster partnership with parents. } \\
\text {-Students get a chance to self-explore new ideas and learning techniques }\end{array}$ \\
\hline 2 & $\begin{array}{l}\text { Challenges of } \\
\text { EiE }\end{array}$ & $\begin{array}{l}\text {-It's expensive. Teachers parents and students were not ready } \\
\text { - connectivity issues, financial implication, unable to comprehend lessons teacher's } \\
\text { inability to use technology. } \\
\text { - At times students lose the track of the lesson. } \\
\text { - Less response from students } \\
\text {-Students are not ready to access online learning resources } \\
\text {-Handling online classes are hectic and thus time-consuming } \\
\text { - Quality of the teaching-learning process is not effective sometimes. } \\
\text {-Network congestions, unable to receive student works on time, no validation of lesson } \\
\text { plans/ low response rates, financial implications } \\
\text {-Lack of orientation thus leading to delivery of unprepared lessons by } \\
\text { - Inequity and lack of accessibility challenge learners who cannot afford it. } \\
\text {-Online learning as a medium is a challenge }\end{array}$ \\
\hline 3 & $\begin{array}{l}\text { Support } \\
\text { needed }\end{array}$ & $\begin{array}{l}\text {-Orientation on online teaching pedagogy is imminent. } \\
\text {-Free wi-fi with high-speed internet connectivity is required. } \\
\text {-Blended learning components may be useful } \\
\text {-As of now not much financial implication is experienced. } \\
\text {-Create awareness to parents on online learning and make the digital device available. }\end{array}$ \\
\hline 4 & $\begin{array}{l}\text { Financial and } \\
\text { personal } \\
\text { implications }\end{array}$ & $\begin{array}{l}\text { - There is the personal financial implication. The approximate monthly data charges } \\
\text { would be 699/- or at the time more when downloading or uploading videos }\end{array}$ \\
\hline 5 & $\begin{array}{l}\text { Views on } \\
\text { strengthening } \\
\text { EiE in } 2021\end{array}$ & $\begin{array}{l}\text {-Training on the use of software, e-learning methods are required for both teachers and } \\
\text { students. } \\
\text {-Blended learning, Teacher PD on the use of technology is most important. An online } \\
\text { learning platform could be built keeping the Bhutanese education context intact. } \\
\text {-Uniform implementation guidelines for all the schools across the nation particularly in } \\
\text { using assessment tools to assess quality teaching and learning } \\
\text { - Should the pandemic continue even in } 2021 \text {, more resources should be ready, the } \\
\text { prioritized curriculum should be discussed between different stakeholders like teachers } \\
\text { in the schools and DEOs. } \\
\text {-Uniform scheduling of lessons in the week or a month/ Need to include science and } \\
\text { social studies/parents need to be well informed and provide support as much as } \\
\text { teachers in the school. }\end{array}$ \\
\hline
\end{tabular}




\begin{tabular}{|l|l|l|}
\hline \multicolumn{1}{|c|}{} & & $\begin{array}{l}\text { - MoE and schools have to work together and make EiE effective as far as possible } \\
\text {-There is a need for a uniform lesson plan and assessment format. }\end{array}$ \\
\hline $\mathbf{6}$ & $\begin{array}{l}\text { Support to } \\
\text { SEN students }\end{array}$ & $\begin{array}{l}\text {-Constant touch with parents and students, lesson modification. } \\
\text {-Pull-out classes and push-in classes were provided to classes IX and X students. Extra } \\
\text { time is given to them to finish their work. } \\
\text {-Special educational needs children who aren't able to walk properly are placed in } \\
\text { ground floor classes. Slow learners especially those who have to learn difficulty } \\
\text { particularly in writing are given extra time during exams just like BCSE does. } \\
\text {-Home visits are made by teachers to support students with mild learning disabilities. } \\
\text {-Provided SIM, MP3 audio to unreachable students } \\
\text { - Differentiated lesson plans are planned and prepared for students with learning } \\
\text { disabilities }\end{array}$ \\
\hline
\end{tabular}

\section{RECOMMENDATION AND CONCLUSION}

Those students who are deprived of learning online due to poor network connectivity, and who could not own smartphones should continue with home visit lesson delivery and interaction by the teachers. Teachers who have not yet commenced in-person home visit meetings with students may have to initiate following all the COVID-19 protocols in place. For those students who did not avail reading materials other than textbooks and SelfInstructional Materials, schools may develop plans to make the school library accessible. This would contribute to keeping children meaningfully engaged and minimize exposure to harmful video games and online videos. The study further recommends the provision of user education to children on smartphones and online content. While it is nearly impossible to deny children from possessing smartphones, it is observed that children are exposed to online games and other social media platforms. The findings from this study lead to carry out more studies on the vulnerability of children's exposure to online games and harmful effects on their learning.

\section{ACKNOWLEDGMENTS}

The Author would like to extend our gratitude to the Education Monitoring Division (EMD) for taking the timely initiative to study the effectiveness of Education in Emergencies (2020). Also, would like to thank the Dzongkhag Education Office for the support rendered during the entire course of the study and remains grateful for the guidance and professional mentorship. Further our heartfelt gratitude to all the parents and students under Thimphu Dzongkhag for participating in the study. Without your true responses, this study would have been rendered incomplete and void.

\section{REFERENCES}

[1] Adarkwah, M. A. (2020). "I'm not against online teaching, but what about us?": ICT in Ghana post Covid-19. Education and Information Technologies, 1-21. https://doi.org/10.1007/s10639-020-10331-z

[2] Alsayed, A. O. (2020). Impact of Coronavirus Pandemic on Education. Journal of Education and Practice.11(13). 108 121.

[3] An overview of quantitative and qualitative data collection methods (n.d.). https://www.nsf.gov/ pubs/2002/nsf02057/nsf02057_4.pdf Back to school. (2020). http://www.oecd. org/education/Ceri/Spotlight-21Coronavirus-special-edition

[4] Bergdahl, N., \& Nouri, J. (2020). Covid-19 and CrisisPromoted Distance Education in Sweden. Technology, Knowledge and Learning, 1-17. https://doi.org/10.1007/s10758-020-09470-6

[5] Dorji, T. (2020). Integration of ICT in Bhutanese Schools Common Obstacles and the Way Forward. The Druk Journal, 6(1). https://drukjournal.bt/journal-issues/

[6] Education in emergencies. (n.d.). http:// s3.amazonaws.com/inee-assets/ 22 resources/UNICEF_Education_in_Emergencies_ToolKit.pdf

[7] Forbes, D. \& Heale, R. (2013). Understanding triangulation in research. file:///C:/Users/User/ Downloads/understandingtriangulation oninresearch.pdf 
[8] Gyem, K., Monger, A., Darnal, J.B., Adhikari, L.M., \& Wangchuk, S. (2020). A descriptive study of confirmed covid-19 cases in Bhutan. J Infect Dis Epidemiol, 6(4) 42. DOI: $10.23937 / 2474-3658 / 1510142$

[9] Hill, J. E., \& Uribe-Florez, L. (2020). Understanding secondary school teachers' TPACK and technology implementation in mathematics classrooms. International Journal of Technology in Education (IJTE), 3(1), 113.https://doi.org/10.46328/ijte.v3i1.8

[10] Kerres, M. (2020). Against All Odds: Education in Germany Coping with Covid-19. Postdigital Science and Education. https://doi.org/10.1007/s42438-020-00130-7

[11] Ministry of Education. (2020). Guidelines for curriculum implementation: Plan for education in an emergency (Education in $\quad$ Emergencies). http:// www.education.gov.bt/wp-content/ uploads/2020/03/Guidelines-forCurriculumImplementationPlan-for-Education-inEmergencyEducation in Emergencies. pdf

[12] Ministry of Education. (2020, a). COVID-19 response plan: Guidelines for Curriculum Implementation Plan for Education in Emergency (EiE). Ministry of Education.

[13] Ministry of Education. (2020, b). Notifications of re-opening schools. http://www.education.gov.bt/index.php/notificationand-guidelines-on-re-opening-of-schools/

[14] Nicolia, S. (2003). Education in Emergencies. London: Save the children. http://s3.amazonaws.com/ ineeassets/resources/doc_1_50_EducationEmertoolkit.pdf

[15] OECD (2020). School Education During COVID-19: Were Teachers and Students Ready? OECD Publishing. Onyema, E. M., Eucheria, N. C., Obafemi, F. A., Sen, S., Atonye, F. G., Sharma, A., \&

[16] Sinclair, M. (2001). Education in emergencies. https:// www.researchgate.net/ publication/44827068_Education_in_ emergencies.

[17] Stiggins, R. J. (1991). Assessment literacy. Phi Delta Kappan, 72(7), 534-39.

[18] Talbot, C. (2013). Education in Conflict Emergencies in Light of the post-2015 MDGs and EFA Agendas. https:// www.norrag.org/fileadmin/Working Papers/Education_in_conflict_emergencies_Talbot.pdf

[19] Zhou, L., Wu, S., Zhou, M., \& Li, F. (2020). 'School's out, but the class' on', the largest online education in the world today: taking china's practical exploration during the covid19 epidemic prevention and control as an example. but class' on', the largest online education in the world today: taking China's practical exploration during the covid-19 epidemic prevention and control as an example. Best Evid Chin Edu. 4(2), 501-519. http://dx.doi.org/10.2139/ssrn.3555520 


\section{Appendix A. Survey Questionnaire to parents}

\begin{tabular}{|l|l|l|}
\hline Sl. No. & Questions & Response \\
\hline 1 & Do you see your child interacting with teachers frequently? & \\
\hline 2 & How long does your child spend time on learning subjects in a day on average? & \\
\hline 3 & How many hours does he/she spend on reading books/newspapers/ magazines, etc. in a day? & \\
\hline 4 & On average, how long does he/she engage in video games \& other online games in a day? & \\
\hline 5 & How long does he/she engage in helping the family? & \\
\hline 6 & How long does he/she engage in physical games and activities? & \\
\hline 7 & How do you support your child's learning? & \\
\hline 8 & How does your child interact with teachers? & \\
\hline 9 & Do you find online learning effective for your child? Justify. & \\
\hline 10 & How much money do you spend on a child's learning in a month? & \\
\hline 11 & Your overall views on online teaching and learning \& recommendations & \\
\hline
\end{tabular}

\section{Appendix B. Survey Questionnaire to students}

\begin{tabular}{|c|c|c|}
\hline Sl. No. & Questions & Response \\
\hline 1 & I enjoy EiE online lessons & \\
\hline 2 & I am learning & \\
\hline 3 & Average hours I spend on online lessons \& assignments per day & \\
\hline 4 & My parents can help me in learning & \\
\hline 5 & I access lessons on (TV, Phone, SIM, Radio, Video, etc.). You can mention more than one medium & \\
\hline 6 & If you are using a phone, which App do you use the most? & \\
\hline 7 & Do you face challenges in using different Apps? & \\
\hline 8 & How frequently do you contact your teachers in a week? & \\
\hline 9 & I have all the textbooks with me & \\
\hline 10 & Do teachers assess tasks given in TV, Radio, SIM lessons? & \\
\hline 11 & How do you clarify your learning doubts? & \\
\hline 12 & What type of support do you receive from teachers? & \\
\hline 13 & What support do you receive from your parents? & \\
\hline 14 & How many hours do you spend reading books/newspapers/magazines/etc. in a week. & \\
\hline 15 & How many hours do you spend on video games and other online games? & \\
\hline 16 & Has your interest in studies been affected by school closure? & \\
\hline 17 & Will you be excited to return to school when it reopens? (Closed schools) & \\
\hline 18 & Did you avail $60 \%$ discount data service? & \\
\hline 19 & No. of hours you spend supporting your parents in a day & \\
\hline 20 & Your overall views on online learning and suggestions & \\
\hline
\end{tabular}

